\title{
More resident positions needed say medical students
}

Seventy-seven anglophone medical school graduates are without a residency position following the first round of the 2005 residency match, underlining the need for more positions, says the Canadian Federation of Medical Students.

Many of these students will go to the US or other countries, "rather than settling for a residency in a field they aren't interested in," says CFMS President Ashley Waddington.

"By not providing an adequate number of residency training positions we are squandering our investment in these young doctors," says Waddington, a second-year student at McMaster University in Hamilton.

The CFMS wants 120 residency positions for every 100 students. This year's ratio was about 106:100.
The number of Enlgish-language residency positions increased this year to 1508 , up from 1404 last year. There were 1428 applicants this year.

The Ontario government is adding 150 new family medicine spots. Waddington says this is "encouraging."

First-round results from the Canadian Resident Matching Service (CaRMS) show 109 of 165 residency positions that remained vacant were in family or rural family medicine. CaRMS expects most of those to be filled after the second round on April 13.

Results indicate $28 \%$ of students graduating from Canada's 13 English-language medical schools made family medicine their first career choice, up from $26 \%$ in 2004. But the College of Family Physicians of Canada says this is still inade- quat, given that more than 3 million Canadians do not have a family doctor.

After the first match round, 15 positions also remained vacant in psychiatry, another specialty where pending retirements have placed pressure on existing practitioners to meet patient needs.

In Quebec, 26 specialist positions remain unfilled after the first round. In all, there are 610 residency positions at the 3 French-language medical schools and McGill University.

Twenty-three of the unfilled positions were in intenal medicine. Michel Giguere at the Conférence des recteurs et des principaux des universités du Québec says these vacancies are likely due to new regulations making it more difficult for residents to move from internal medicine to subspecialties. - Laura Eggertson and Barbara Sibbald, CMAJ

\section{INFECTIOUS DISEASE}

\section{Russia underestimates HIV/AIDS incidence}

A highly detailed statistical investigation of Russian HIV/AIDS data funded by the US Agency for International Development suggests the Russian government dramatically underestimates what may be the world's fastest-growing AIDS epidemic.

Murray Feshbach, a demographer at the Woodrow Wilson International Center for Scholars in Washington, DC, who has tracked Russian AIDS since the 1980 s, used a variety of sources including Russian Army physicians' reports, morbidity and mortality data from a number of diseases associated with AIDS and data provided by the Russian Ministry of Health's Federal AIDS Center in Moscow, to conclude there are as many as 900000 Russians infected with HIV rather than the 300000 cases officially reported in late 2004.

Feshbach also concluded
Russian HIV/AIDS deaths are severely underreported. He suggests the official figure of 4780 deaths to August 2004 should be revised to a total of 17500 .

HIV began spreading among intravenous drug users in Russia in the 1990s but heterosexual sex is now the epidemic's main transmission path. "It is perhaps too late to prevent the concentrated epidemic from eventually generalizing to the entire population," says Feshbach, who is urging aggressive use of drug therapy, prevention and education. Since 2001 , more than $80 \%$ of reported Russian HIV cases were in the 15 to 29 age group; in Western $\mathrm{Eu}-$ rope and North America 70\% of reported cases are among people over 30. The number of affected Russian women is also on the rise: in 2000, they accounted for $20 \%$ of cases; by 2003 they accounted for one third.

Figures from Russia's Federal

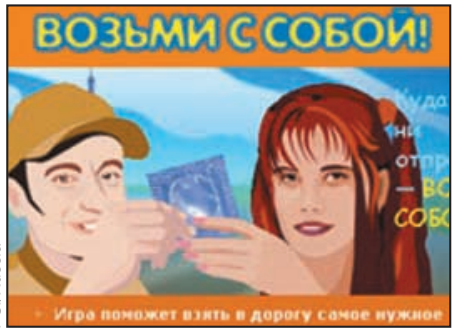

Russian public health initatives, such as this "Take It With You" campaign, are emerging.

AIDS Center have been repeatedly challenged by UNAIDS and by the Center's director, Vadim Pokrovsky. Like Feshbach, UNAIDS and Pokrovsky have suggested that the official figures should be tripled.

Feshbach says the unreliability of official Russian data is due to physicians who are unfamiliar with AIDS symptoms and cases where families wish to conceal AIDS as the cause of death. Paul Webster, Toronto 